Instructions for authors, subscriptions and further details:

\title{
http://mcs.hipatiapress.com
}

\section{Masculinidades Incómodas: Jóvenes, Género y Pobreza}

Juan Carlos Peña Axt ${ }^{1}$

1) Universidad Autónoma de Chile, Chile

Date of publication: June $21^{\text {th }}, 2019$

Edition period: June 2019- October 2019

To cite this article: Peña Axt, J.C. (2019). Masculinidades Incómodas: Jóvenes, Género y Pobreza. [Review of the book]. Masculinities and Social Change 8(2), 218-219. doi: 10.17583/MCS.2019.4375

To link this article: http://dx.doi.org/10.4471/MCS.2019.4375

\section{PLEASE SCROLL DOWN FOR ARTICLE}

The terms and conditions of use are related to the Open Journal System and to Creative Commons Attribution License (CC-BY). 


\section{Reviews (I)}

Artiñano, N. A. (2015). Masculinidades incómodas: Jóvenes, género y pobreza. Buenos Aires: Espacio Editorial.

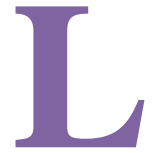

a masculinidad en la actualidad es una temática que se aborda en libro de Artiñano nos recupera un debate relevante en los estudios de género, más concretamente en el análisis de las masculinidades. Este debate está conectado con la variable de clase social que Paul Willis ya abordó en su principal obra: Aprendiendo para trabajar: Como los chicos de clase obrera consiguen trabajos de clase obrera. Según Artiñano los chicos jóvenes con problemas de pobreza reproducen los patrones de género tradicionales, perpetuando de esta forma un tipo de masculinidad tóxica que va muy ligada a problemáticas sociales como la violencia y la criminalidad.

A partir de un trabajo metodológico de naturaleza cualitativa, el autor, nos ofrece una reflexión profunda sobre la dificultad de ser joven en América Latina, al mismo tiempo que también ahonda en el echo de no disfrutar de una situación económica segura. En el libro se plantea como un auténtico challenge la construcción de la masculinidad durante la adolescencia y la juventud. Uno de los argumentos que se utilizan está relacionado con las prácticas contrahegemónicas que suelen ser una característica clave en esta etapa de la vida. Sin embargo, también se subraya que la definición de la masculinidad también va acompañada de mantener los privilegios propios de la masculinidad hegemónica.

Más allá de este análisis, Artiñano argumenta que se está desarrollando un cambio en las últimas décadas debido a las transformaciones sociales que en este campo están viviendo las sociedades modernas. La incorporación de la mujer en el mundo laboral, las políticas de igualdad, los grupos de hombres igualitarios están influenciando la definición de las identidades

2019 Hipatia Press

ISSN: 2014-3605

DOI: $10.17583 / \mathrm{MCS} .2019 .4375$ 
masculinas. En este sentido, el libro hace referencia a autores como Seidler, Braslavsky y Giddens para ejemplificar que los hombres están inmersos en una ambivalencia debido a los influjos culturales dirigidos a mantener los privilegios de poder, en contradicción a las prácticas que lo cuestionan y buscan establecer relaciones de género más igualitarias.

Todo el análisis desarrollado en el libro es de gran utilidad para el planteamiento final que se realiza sobre la importancia de abordar las temáticas de género en la disciplina de Trabajo Social. En ocasiones ha sido un ámbito olvidado o abordado desde el asistencialismo, de modo que representa un reto importante para los futuros y futuras profesionales de este campo.

Juan Carlos Peña Axt, Universidad Autónoma de Chile. 